\title{
The Principles of Cancer: A Metaphor of Life?
}

\author{
Authors: Roland Mertelsmann, Alexandros Spyridonidis \\ Submitted: \\ 11. June 2019 \\ Published: \\ Volume: \\ Issue: \\ Affiliation: \\ Languages: \\ Keywords: \\ Categories: \\ DOI: \\ 24. June 2019 \\ 6 \\ 6 \\ University of Patras, Dept. of Medicine, Stem Cell Transplantation, \\ Patras, Greece \\ English \\ cancer, metaphor, life, artificial intelligence \\ Life Sciences, Medicine \\ 10.17160/josha.6.6.572
}

Abstract:

While cancer is a complex disease with a multitude of clinical presentations, a few principles can be discerned. Cancer is old; it existed already in the earliest multicellular organisms. Cancer is natural; the older you get, you get cancer. Cancer can be considered as a "metaphor of life"; mutations are the backbone of cancer but also a prerequisite for the evolution of species (life). Still, many questions remain open: What is cancer, why does it exist and why can we not fight it successfully? Here, we propose entropy as the continuous-time stochastic principle (carcinogen) that forces to create the "parts" (mutations) and dictates them to reconstitute the "whole" (cancer). Artificial intelligence can help us to capture this "big picture" of cancer and to develop cancer therapies towards decreasing, instead of increasing, cellular entropy. Ageing process is probably orchestrated from the same entropy principle. Visualizing and calculating cellular entropy might help us to identify the differences between ageing process and cancer. 


\title{
The Principles of Cancer Cancer: A Metaphor of Life?
}

\author{
Alexandros Spyridonidis \\ University of Patras, Dept. of Medicine, Stem Cell Transplantation, Patras, Greece
}

\section{Roland Mertelsmann}

Department of Medicine/ Oncology, Hematology, and Stem Cell Transplantation, Freiburg University Medical Center, Freiburg, Germany

\section{Abstract}

While cancer is a complex disease with a multitude of clinical presentations, a few principles can be discerned. Cancer is old; it existed already in the earliest multicellular organisms. Cancer is natural; the older you get, you get cancer. Cancer can be considered as a "metaphor of life"; mutations are the backbone of cancer but also a prerequisite for the evolution of species (life). Still many questions remain open: What is cancer, why does it exist and why can we not fight it successfully? Here, we propose entropy as the continuous-time stochastic principle (carcinogen) that forces to create the "parts" (mutations) and dictates them to reconstitute the "whole" (cancer). Artificial intelligence can help us to capture this "big picture" of cancer and to develop cancer therapies towards decreasing, instead increasing, cellular entropy. Ageing process is probably orchestrated from the same entropy principle. Visualizing and calculating cellular entropy might help us to identify the differences between ageing process and cancer. 
While cancer is a complex disease with a multitude of clinical presentations, a few principles can be discerned. "Everything should be made as simple as possible, but not simpler." (Albert Einstein). Cancer is much older than the human race. Cancer has been found in the one billion years old hydra, one of the earliest organisms to evolve out of single-celled primitive organisms and has been described in all known multicellular species ${ }^{1}$. What is cancer, and why does it exist? The first belief that cancer was caused by the gods was called into question by Hippocrates who suggested natural, instead of religious, causes of cancer. His disciples such as the Greek citizen of Rome Claudius Galen made internal carcinogens (e.g. bile, other secretions) responsible for cancer. It was only in the $19^{\text {th }}$ century when the theory of exogenous causes of cancer (e.g. radiation, tobacco, viruses) emerged. The current thinking is that cancer is the result of mutations, thus cancer is an acquired genetic disease. While some of them can be traced to external carcinogens, about $30 \%$ of these are spontaneous ${ }^{2,3}$. With time, our cells are at risk to succumb to random cancer-causing mutations ${ }^{4}$. "Cancer is so simple and so natural. The older you get, this is just one of the things that happens as the clock ticks." (Richard E. Smalley, 1996 Nobel Prize for Chemistry). In a simplistic logical prediction, cancer rates should correlate with cell division rate in a given organ, genetically defined mutation risk (for elephants see references 5 and 6), exposure to exogenous carcinogens, body size and age ${ }^{4,7}$ as cells will have plenty more opportunities to acquire mutations. However, elephants who have trillions more cells than us and live a long time, i.e. up to 80 years, have lower cancer rates and mice who live short and have far fewer cells than humans are extremely cancer-prone (Peto's paradox $)^{8}$. These observations demonstrate the 5 major factors impacting on cancer development and probably also on the subsequent evolution of cancer clones $^{9,10}$.

\section{Mutations are not cancer.}

Billions of dollars and decades of research trying to untangle the fundamental mysteries of cancer spawned a huge amount of "big data". Why is then the 40-year "War on Cancer" declared by President Richard M. Nixon still not yet won? "What we observe is not nature itself, but nature exposed to our method of questioning" (Werner Heisenberg) could be one explanation. Besides that, each information that is presented in the millions of scientific papers reveal only a tiny "part", a "snapshot" of the biological process we are looking at. Carcinogenesis is not only complex and multistep but also a "moving target" with cancer cells finding alternative pathways to survive and progress. How to understand cancer using the current available knowledge? "The whole is more than the sum of its parts" (Aristoteles 384-322 BC). Words are not literature, pixels are not an image ("Gestalt"-theory) and mutations are not a cancer. Ultimately, cancer research could be progressed 
by shifting our focus from the "parts" to uncover the continuous-time stochastic principles that dictate the "parts" to reconstitute the "whole". The question is, what orchestrates mutations to cancer?

\section{Entropy is probably the most powerful carcinogen.}

"Everything flows" (Heraclitus, 535-475 B.C.). Life, and all its constituents (cells, atoms, molecules, even genes) are always in motion. All natural systems tend to progress in the direction of increasing disorder (e.g. ice always melts) or the other way around "Disorder increases with time because we measure time in the direction in which disorder increases" (Stephen W. Hawking). This time's arrow transformation towards a state of increased disorder is called entropy ( $\varepsilon v$ in, $\tau \rho o \pi \eta$ transformation). Thus, the strange, uncontrolled cell growth we call cancer, can be viewed as a state of increased entropy ${ }^{11-15}$. Decreasing entropy and maintaining order needs energy (e.g. to repair a broken glass). DNA repair mechanisms require an excess amount of energy to maintain DNA integrity.

\section{„Gestalt" (Big Picture) Recognition with artificial intelligence}

Also accepting a simplistic view implying that a mutation could deregulate in a 5-«concentration» scale one of the ten "hallmark" cancer pathways described by Hanahan and Weinberg ${ }^{16}$ and this can be done in 10 different time points during the cell life, then $10 \times 5^{10}$ experiments would be needed to study this pathway, something which cannot been done in the "wet lab". In silico computational analysis of the huge amount of -omic data is nowadays more and more used for modeling complex molecular processes to functionally interpret these data and to predict natural processes. However, since we cannot know the entirety of actual mechanisms, parameters and measurements and how these interact simultaneously and over time, we need self-teaching artificial intelligence for predictive analytics. The most important factor in applying "Machine Learning Tools" is to choose a clear endpoint (ask the right question) and have benchmark patterns against which to assess outputs. Afterwards, the "Machine Learning Intelligence" seeks all possible paths that could answer the question. For studying cancer trajectories, "Machine Learning Tools" could be used to ask how -omic signaling interaction networks drive cells to an increased state of molecular disorder (and thus entropy). Is it possible to calculate entropy of the cells? Mathematical models based mainly on information theory (Shannon-Hartley theorem) have been used to calculate entropy in many biological systems, including cells ${ }^{17-21}$. Another possibility is to use fractal mathematics and fractal graphics to calculate and visualize entropy. For example, Azua-Bustos and Vega ${ }^{22}$ used fractal geometry analysis to quantify the degree of entropy difference between living processes and argued that this methodology could be used for finding life "as we don't know it" elsewhere in the Universe, since "Life feeds on negative entropy" (Erwin Schrödinger). Fractals are not limited to geometric patterns, but can also describe natural, poly-dimensional processes in time. " $A$ doctrine of 
nature can only contain so much science proper as there is in it of applied mathematics." (Immanuel Kant, 1724-1804). We should look out and develop mathematical models and/or nano-sensors that could capture cellular entropy ${ }^{23-27}$. In a second step, we could apply machine learning technology to drive wet lab experiments ${ }^{28}$.

\section{The War on Cancer Revisited?}

Cancer therapies should aim to decrease cellular entropy. Chemotherapeutics induce DNA damage and probably increase entropy in the cell to a state that some of them collapse. Do epigenetic therapies alter the cellular signaling networking towards better order (and thus negative entropy) by "switching on" gene information into usable energy that restores differentiation? How are the molecular therapies altering cellular entropy? Do they help to reorganize the signaling network from a higher degree of disorder to a more ordered structure or do the opposite and increase the molecular entropy? These answers are essential, so that cancer therapy could be optimized based on the calculation of negative and positive entropy they induce. This concept, however, bears limitations since a cancer cell is not a "closed" biological system, but exists in a complex ecosystem (organism) with permanent exchange of substances and energy between the cancer cell and the other parts of this ecosystem ("Trans-system Pathophysiology"). The principles that coordinate these interactions are not completely ununderstood, but in all probability are also dictated by the natural law of entropy. Does the immune system in a cancer patient fail to response to the mutation-linked cancer neo-antigens (and thus maintain tissue integrity and decrease ecosystem entropy) or does it increase the cellular entropy and support cancer growth ${ }^{29}$ How can it be explained that the frequency of mutated, high entropic hematopoietic cells (clonal hematopoiesis) is associated with increased risk of myocardial infraction? ${ }^{30-31}$. "Nature does nothing in vain" (Aristoteles). Cancer is part of life. We will rarely cure it, but we always be there and be able to help by using the human self-teaching Intelligence called experience. "Observe, record, tabulate, communicate. Use your five senses. Learn to see, learn to hear, learn to feel, learn to smell, and know that by practice alone you can become expert." (William Osler). Since cancer is such an integral part of the ageing process, understanding cancer will also help us to better understand the ageing process and might eventually help us to delay or at least ameliorate the ageing process ${ }^{32}$.

\section{References}

1. Domazet-Lošo T, Klimovich A, Anokhin B, Anton-Erxleben F, Hamm MJ, Lange C, Bosch TC. Naturally occurring tumours in the basal metazoan Hydra. Nat Commun. 2014; 5:4222.

2. B. Tomasetti C, Vogelstein B. Variation in cancer risk among tissues can be explained by the number of stem cell divisions. Science 2015; 347: 78-81.

3. C Song M, Vogelstein B, Giovannucci EL, Willett WC, Tomasetti C. Cancer prevention: Molecular and epidemiologic consensus. Science. 2018; 361: 1317-1318. 
4. Martincorena I, Fowler JC, Wabik A, Lawson ARJ, Abascal F, Hall MWJ, Cagan A, Murai K, Mahbubani K, Stratton MR, Fitzgerald RC, Handford PA, Campbell PJ, Saeb-Parsy K, Jones PH. Somatic mutant clones colonize the human esophagus with age. Science. 2018; 362:911-917

5. Ferris E, Abegglen LM, Schiffman JD, Gregg C. Accelerated Evolution in Distinctive Species Reveals Candidate Elements for Clinically Relevant Traits, Including Mutation and Cancer Resistance. Cell Rep. 2018; 22: 2742-2755

6. Abegglen LM, Caulin AF, Chan A, Lee K, Robinson R, Campbell MS, Kiso WK, Schmitt DL, Waddell PJ, Bhaskara S, Jensen ST, Maley CC, Schiffman JD. Potential Mechanisms for Cancer Resistance in Elephants and Comparative Cellular Response to DNA Damage in Humans. JAMA. 2015; 314: 1850-60

7. Xie M., Lu C., Wang J., McLellan M.D., Johnson K.J., Wendl M.C., McMichael J.F., Schmidt H.K., Yellapantula V., Miller C.A. et al. Age-related mutations associated with clonal hematopoietic expansion and malignancies. Nat. Med. 2014; 20: 1472-1478

8. Leroi AM, Koufopanou V, Burt A. Cancer selection. Nat Rev Cancer. 2003; 3: 226-231.

9. Jenny Groten, Christoph Borner, Roland Mertelsmann. Understanding and Controlling Cancer: The Hallmark Concept Revisited - Chance, Evolution and Entropy. Journal of Science, Humanities and Arts. 2016; 3(7); DOI: 10.17160/josha.3.7.252

10. Martincorena I, Raine KM, Gerstung M, Dawson KJ, Haase K, Van Loo P, Davies H, Stratton MR, Campbell PJ. Universal Patterns of Selection in Cancer and Somatic Tissues. Cell. 2017 ; 171: 1029-1041

11. Kayser K, Kayser G, Eichhorn S, Biechele U, Altiner M, Kaltner H, et al. Association of prognosis in surgically treated lung cancer patients with cytometric, histometric and ligand histochemical properties: With an emphasis on structural entropy. Analytical and Quantitative Cytology and Histology 1998; 20: 313-320.

12. West J, Bianconi G, Severini S, Teschendorff AE. Differential network entropy reveals cancer system hallmarks. Sci. Rep. $2012 ; 2: 802$

13. Riggs JE. Carcinogenesis, genetic instability and genomic entropy: Insight derived from malignant brain tumor age specific mortality rate dynamics. Journal of Theoretical Biology. 1994; 170: $331-338$

14. Teschendorff AE, Severini S. Increased entropy of signal transduction in the cancer metastasis phenotype. BMC Systems Biology. 2010; 4: 104.

15. M. Tarabichi, A. Antoniou, M. Saiselet, J. M. Pita, G. Andry, J. E. Dumont, V. Detours, C. Maenhaut. Systems biology of cancer: entropy, disorder, and selection-driven evolution to independence, invasion and "swarm intelligence". Cancer Metastasis Rev. 2013; 32: 403-421.

16. Hanahan D \& Weinberg RA. Hallmarks of Cancer: The Next Generation. Cell 2011; 144, 646-674.

17. van Wieringen WN, van der Vaart AW. Statistical analysis of the cancer cell's molecular entropy using high-throughput data. Bioinformatics. 2011; 27: 556-563

18. West J, Bianconi G, Severini S, Teschendorff AE. Differential network entropy cancer system hallmarks. Sci Rep. 2012; 2: 802

19. Banerji CR, Miranda-Saavedra D, Severini S, Widschwendter M, Enver T, Zhou JX, Teschendorff AE. Cellular network entropy as the energy potential in Waddington's differentiation landscape. Sci Rep. 2013 ;3: 3039 
20. Teschendorff AE, Sollich P, Kuehn R. Signalling entropy: A novel network-theoretical framework for systems analysis and interpretation of functional omic data. Methods. 2014; 67: 282-293

21. Tseng CY, Tuszynski J. Entropic analysis reveals a connection between the recurrence of cancer and chemotherapy. Saudi J Biol Sci. 2015; 22: 674-678

22. Azua-Bustos, A., Vega-Martínez, C. The potential for detecting 'life as we don't know it' by fractal complexity analysis. International Journal of Astrobiology, 2013; 12: 314-320

23. Georg M, Fernández-Cabada T, Bourguignon N, Karp P, Peñaherrera AB, Helguera G, Lerner B, Pérez MS, Mertelsmann R. Development of image analysis software for quantification of viable cells in microchips. PLoS One. 2018; 13: e0193605

24. Xingyi Ma, Phuoc Long Truong, Nguyen Hung Anha, Sang Jun Sima. Single gold nanoplasmonic sensor for clinical cancer diagnosis based on specific interaction between nucleic acids and protein, Biosensors and Bioelectronics, 2015; 67: 59-65

25. Seonghwan Lee, Hunho Jo, Jin Her, Ho Yong Lee, Changill Ban. Ultrasensitive electrochemical detection of engrailed-2 based on homeodomain specific DNA probe recognition for the diagnosis of prostate cancer. Biosensors and Bioelectronics, 2015; 66: 32-38

26. Kim D, Shin H, Sohn KA, Verma A, Ritchie MD, Kim JH. Incorporating inter-relationships between different levels of genomic data into cancer clinical outcome prediction. Methods. 2014; 67: $344-53$

27. Bichen Zheng, Sang Won Yoon, Sarah S. Lam, "Breast cancer diagnosis based on feature extraction using a hybrid of K-means and support vector machine algorithms", Expert Systems with Applications, 2014; 41: 1476-1482

28. Mertelsmann R, Duyster J, Follo M, Perez M, Lange S. Verfahren zur Einrichtung einer Apparatur für biologische Prozesse und Apparatur für biologische Prozesse. Patent applied 2018 29. Janssen LME, Ramsay EE, Logsdon CD, Overwijk WW. The immune system in cancer metastasis: friend or foe? J Immunother Cancer. 2017; 5: 79

30. Jaiswal S, Natarajan P, Silver AJ, Gibson CJ, Bick AG, Shvartz E, McConkey M, Gupta N, Gabriel S, Ardissino D, Baber U, Mehran R, Fuster V, Danesh J, Frossard P, Saleheen D, Melander O, Sukhova GK, Neuberg D, Libby P, Kathiresan S, Ebert BL. Clonal Hematopoiesis and Risk of Atherosclerotic Cardiovascular Disease. N Engl J Med. 2017; 377: 111-121

31. Fuster JJ, MacLauchlan S, Zuriaga MA, Polackal MN, Ostriker AC, Chakraborty R, et al. Clonal hematopoiesis associated with TET2 deficiency accelerates atherosclerosis development in mice. Science. 2017; 355: 842-847

32. Faletti L, Mertelsmann R, Zirlik K. Unraveling the syndrome of the age-associated diseases: Cancer, Cardiovascular, and Neurological disorders. Common pathways and novel therapeutic strategies. Journal of Science, Humanities and Arts. 2019; Vol 6, Issue 2: DOI: 10.17160/josha.6.2.539 